\title{
Housing type and risk of malaria among under-five children in Nigeria: evidence from the malaria indicator survey
}

\author{
Oyewale M. Morakinyo ${ }^{1}$, Folusho M. Balogun ${ }^{2^{*}}$ (1) and Adeniyi F. Fagbamigbe ${ }^{3}$ (D)
}

\begin{abstract}
Background: Malaria remains one of the major causes of morbidity and mortality among under-five (U5) children in Nigeria. Though different environmental factors have been assessed to influence the distribution and transmission of malaria vectors, there is a dearth of information on how housing type may influence malaria transmission among U5 children in Nigeria. This study assessed the relationship between housing type and malaria prevalence among U5s in Nigeria.
\end{abstract}

Methods: A cross-sectional analysis of the nationally representative 2015 Nigeria malaria indicator survey data was done. A representative sample of 8148 households in 329 clusters was selected for the survey. Children aged 6-59 months in the selected households were tested for anaemia and malaria using the rapid diagnostic test (RDT) and the microscopy. Data were analysed using descriptive statistics, Pearson Chi square $\left(x^{2}\right)$ and logistic regression models at $5 \%$ level of significance.

Results: The odds of malaria infection was significantly higher among older children aged 24-59 months (aOR $=4.8$, $\mathrm{Cl} 2.13-10.99, \mathrm{p}<0.001)$, and children who lived in houses built completely with unimproved materials $(\mathrm{aOR}=1.4$, Cl 1.08-1.80, $\mathrm{p}=0.01$ ). Other predictors of malaria infection include living in a rural area (aOR=1.5, Cl 1.25-1.91, $p=0.01)$, ever slept under a long-lasting insecticide-treated net $(a O R=1.1, C l 0.26-4.79, p=0.89)$ and in a room not sprayed with insecticide $(\mathrm{aOR}=1.2, \mathrm{Cl} 0.64-2.31, \mathrm{p}=0.56)$. Children who were malaria positive showed a higher prevalence of severe anaemia on RDT (87.6\%) and Microscopy (67.4\%) than those who were not anaemic (RDT $=31.6 \%$, Microscopy $=12.9 \%$ ).

Conclusions: Non-improved housing predicted malaria infection among U5s in Nigeria. Improved housing is a promising means to support a more integrated and sustainable approach to malaria prevention. Education of the Nigerian people on the role of improved housing on malaria protection and empowerment of the public to adopt improved housing as well as overall enlightenment on ways to prevent malaria infection can help to augment the current malaria control measures among U5 children.

Keywords: Housing type, Malaria, Under-five, Rapid diagnostic test, Microscopy

\section{Background}

Malaria, an ancient threat to human health, remains a primary cause of morbidity and mortality globally $[1,2]$. The 2016 world malaria report indicated that 212 million cases and 429,000 deaths were recorded in 2015 [3].

\footnotetext{
*Correspondence: folushom@yahoo.com

${ }^{2}$ Institute of Child Health, College of Medicine, University of Ibadan, Ibadan, Nigeria

Full list of author information is available at the end of the article
}

Two-third of this deaths occurred among under-five (U5) children in Africa [3]. About 25\% of malaria burden in Africa [4] occurred in Nigeria where 60\% of outpatients' visits and $30 \%$ of hospital admissions are as a result of malaria [5].

Most often, patients present with non-specific symptoms, such as fever, rigors, and chills. Severe malaria develops mainly among children and may manifest as extreme weakness, impaired consciousness, severe 
anaemia, respiratory distress, convulsions, and hypoglycaemia, among other symptoms [6]. The occurrence of long-term neurological sequelae from severe malaria [7], subtle developmental and cognitive impairments as a result of both severe and uncomplicated episodes [8] have been reported in children. Moreover, anaemia is one of the complications that accompany malaria infections and it plays a significant role in its morbidity and mortality [9].

However, recent epidemiological reports have signified a reduction in the global burden of malaria $[2,10]$. This has been attributed to the up-scaling up of malaria prevention and control interventions, including the use of long-lasting insecticide-treated nets (LLINs), indoor residual spraying (IRS), intermittent preventive therapy for pregnant women (IPTp), improved use of malaria rapid diagnostic tests (RDTs) and effective treatments using artemisinin-based combination therapy (ACT) [10, $11]$.

Nevertheless, the rising problem of insecticide-resistant mosquitoes is hindering the usefulness of some of these interventions, with some species of mosquitoes in Western and Southern Africa being resistant to the currently available classes of insecticide in public health [12-14]. Researchers have pointed out the likelihood of resistant mosquitoes surviving up to a thousand times in the minimal concentration of insecticide that normally kills susceptible mosquitoes [14-16]. Instances of bloodfed mosquitoes present in LLINs or resting on sprayed walls have also been reported [14-16]. Continuous use of these interventions suggests that lessons have not been learnt from the problems of insecticide resistance which occurred in the $50 \mathrm{~s}$ and $60 \mathrm{~s}$ during the global malaria eradication programme [17-19].

Different malaria control programmes have been introduced, and these include the WHO Global Technical Strategy for Malaria 2016-2030 (GTS), the complementary Roll Back Malaria (RBM), and the multi-sectoral Action and Investment to Defeat Malaria 2016-2030 (AIM). The goals of these programmes are to achieve a $90 \%$ decline in mortality and case incidence of malaria, complete eradication from 35 countries by 2030 and avert the re-introduction into malaria-free areas. Although these are laudable initiatives, there is an obvious and urgent need to pay more attention to the newer interventions which are stated in the guidelines of these programmes as this will complement the previous reliance on the use of LLINs and IRS [20, 21].

The role of housing in reducing the burden of malaria resonated throughout the AIM framework [11, 20]. There is a growing interest in the desire to use 'modern' housing as an intervention against malaria burden as recently illustrated in the new RBM work stream on malaria and housing [11]. Housing is an important determinant of health and quality of life [22]. The design of a house contributes to the incidence of Plasmodium falciparum infection [23, 24]. Researchers have reported that living in an improved housing played a significant role in the eradication of malaria in the United States and its reduction in Europe [25, 26]. It played a vital role in controlling human exposure to mosquitoes and vector-borne diseases [27]. A $42 \%$ lower odds of malaria infection and a 54-65\% lower incidence of clinical malaria have been reported among occupants of improved housing than unimproved houses in The Gambia [11].

Although the possibility for an association between housing type and malaria incidence has been established, the evidence base remains sparse compared to the evidence associated with the use of LLINS or IRS. In Nigeria, there is a dearth of information on how housing type may influence malaria transmission across locations, regions, and household wealth among children U5. The objectives of this study were to describe the pattern of malaria parasite infection among U5 children and to determine the relationship between housing characteristics and malaria infection among this age group in Nigeria. The significance of the current study lies in its ability to provide an evidence-based recommendation on the importance of improved housing to accelerating the progress towards the control and elimination of malaria on a large scale in Nigeria. It will also influence the formulation of policy that will promote the design of healthy houses which can contribute to the reduction in the threat of malaria among children U5 years of age.

\section{Methods}

\section{Study area}

This study was conducted in Nigeria, a federal republic in West Africa. Administratively, it is divided into 36 states and a federal capital territory (FCT). These states are further classified into six geopolitical zones: North-West, North-Central, North-East, South-East, South-West, and South-South. In each of the geopolitical zones, the people are similar in nature and unique in their ways of life including health-related characteristics and housing types.

\section{Data source}

This study utilized data from the 2015 Nigeria Malaria Indicator Survey (NMIS). The 2015 NMIS was designed to provide useful information on malaria indicators and prevalence across the country. This data was jointly collected by the National Malaria Elimination Programme (NMEP), the National Population Commission (NPC), the National Bureau of Statistics (NBS), and the Malaria Partnership in Nigeria. 


\section{Sampling}

The Nigeria National Population and Housing Census conducted in the year 2006 served as the sampling frame for the NMIS 2015 study. Each of the 36 states in Nigeria was classified into Local government areas (LGAs), and each LGAs into localities. In each locality were also enumeration areas (EAs) or clusters which formed the primary sampling unit. Selection of study participants was in two stages. In the first stage, a total of 333 EAs (comprising 9 EAs per state, including the FCT) were randomly selected. Twenty-five households in each EAs that were selected by equal probability systematic sampling represents the second stage of sampling. All women who were between 15 and 49 years of age, residing permanently in the households or visitors who were present on the night prior the start of the survey were enlisted. The sample size was calculated in such a way that 1338 women in each of the six geopolitical zones participated in the study. The full description of field procedures are well stated in the full report of the surveys [28].

\section{Data collection procedure}

Data collection took place between October and November 2015. Questionnaire was used to obtain data about malaria prevention activities that the women practice and blood samples were taken from children 6 to 59 months to screen for anaemia and malaria parasite [28].

\section{Laboratory procedures}

\section{Rapid diagnostic test for malaria}

A drop of blood from the finger/heel prick was also used for malaria rapid diagnostic test (RDT) using SD BIOLINE Malaria Ag P.f (HRP-II) ${ }^{\mathrm{TM}}$ (Standard Diagnostics, Inc.) to detect the histidine-rich protein II antigen of $P$. falciparum. All the field laboratory scientists were trained to perform RDT according to the manufacturer's instruction. An applicator was used to draw up a small volume of blood which was placed in the well of the testing device and 2 drops of the buffer added to the other well. The result was read after $15 \mathrm{~min}$. Results were then given to the parent/caregiver of the children and also recorded in the biomarker questionnaire. Children with positive RDT were given age-appropriate malaria treatment according to the Nigeria national malaria treatment guidelines as long as they were not currently on treatment for malaria and had not had such treatment 2 weeks prior the survey [28].

\section{Malaria diagnosis by microscopy}

Both thick and thin films were prepared on the field using slides. Each slide was given a bar code label which was recorded in each biomarker questionnaire and the blood sample transmittal form that was used to track the blood samples from the point of collection to the laboratory. The slides were dried and transported in slide boxes. Thin smears were fixed using absolute methanol at the end of each day. The slides were then stained and read. Thick smears were examined first to determine the presence of malaria parasite. The thin smears for all positive thick smears were then examined to determine the species of malaria parasite that was present [28].

\section{Testing for anaemia}

Trained health technicians collected blood samples from the children using a finger or heel pricks that were carried out with a single use retractable, spring loaded, sterile lancet. Blood was then collected in a microcuvette. A battery operated portable $\mathrm{HemoCue}^{\circledR}$ analyser was used for haemoglobin analysis on site and results were obtained within $1 \mathrm{~min}$. The results were recorded in the biomarker questionnaire. Both verbal and written results were then given to the child's parents/caregiver. Parents whose children had haemoglobin less than $8 \mathrm{~g} / \mathrm{dl}$ were counselled and given referral letter to a health facility for proper care and the household was given a brochure showing the causes and prevention of anaemia [28].

\section{Description of variables}

The dependent variable was the outcome of the malaria tests that was determined using RDT and microscopy. Due to wide discrepancies between the outcomes of the two tests, data was analysed along the two outcomes.

The main independent variable was housing type that was classified as either improved or unimproved based on the materials with which the floor, roof, and wall were built. The flooring materials were categorized into either "Improved materials" consisting of cement, ceramic tiles, vinyl asphalt strips, parquet and polished wood or "Unimproved materials" which were made up of earth, sand, dung, rudimentary, wood planks, palm, bamboo, and others $[29,30]$.

The wall materials were categorized as either "Improved materials" (cement, stone with lime/cement, cement blocks and bricks) or "Unimproved materials" (no wall, cane/palm/trunks, dirt, rudimentary, bamboo with mud, stone with mud, uncovered adobe, plywood, and others. Roofing materials were categorized into "Improved materials" (Cement and roofing shingles) and "Unimproved Materials" (no roof, thatch/palm leaf, sod, rudimentary, rustic mat, palm/bamboo, wood planks, cardboard, wood, and others) [29, 30]. All the building materials were then categorized as (i) totally improved-wherein the roofing, wall and floor materials were all improved, (ii) Partially improved-wherein only one or two of the roofing, wall and floor materials were 
all improved and (iii) Unimproved-wherein none of the roofing, wall and floor materials was improved.

Other independent variables include household wealth index, age, and sex of children, mother's education, place of residence, region, location, sleeping under longlasting insecticide-treated net or any ever treated nets, fever in last 2 weeks, and having anaemia. The ages of under-five children were categorized into 0-6, 7-23, and 24-59 months as used in a study by Carvajal-Vélez et al. [31].

\section{Data analysis}

Data were analysed using Stata version 14. Basic descriptive statistics were used in describing the distribution of children and the malaria prevalence by the independent variables (flooring materials, wall materials, roofing materials, all building materials, wealth index, age, sex, mother's education, place of residence, region, location, sleeping under long-lasting insecticide-treated net or any ever treated nets, having fever in last 2 weeks, and having anaemia). Logistic regression models were used in identifying the risk factors of malaria among the children. Bivariate logistic analysis was conducted in order to identify individual candidate variables. All significant variables at bivariate level (p-value less than 0.10 ) were included in the multiple logistic regression as shown in Tables 5, 6. The presence of other variables were controlled by accounting for confounders to obtain the adjusted odds ratio in the two Tables. At the level of multivariate analysis, three models were used to define the relationship between malaria prevalence and housing type. Model 1 is the bivariate model that examined the relationship between housing type and prevalence of malaria while model 2 included the dependent variable, housing type, and the use of treated nets. Model 3 comprised the dependent variable, housing type, use of treated nets, and other independent variables. Data were weighted and significance was evaluated at $5 \%$.

\section{Results}

In all, a total of 6991 children were captured in the survey among which 5753 and 6025 were tested for malaria parasite using the RDT and microscopy methods, respectively. Table 1 shows the distribution of U5 children tested for malaria parasite using RDT and Microscopy. The percentage of children positive for malaria increased with increase in age for both RDT and microscopy tests $(\mathrm{p}<0.001)$, and most prevalent among male children. A greater proportion of U5 children who were malaria positive for RDT and microscopy reside in rural areas, and in the North west geopolitical zone.
Moreover, malaria prevalence reduces with increasing wealth quintile and place of residence $(\mathrm{p}<0.001)$. For instance, children who belonged to the richest wealth quintile had a lesser percentage of malaria positives (RDT+: $12.7 \%$, Micro+: $4.3 \%$ ) compared to those in the poorest wealth quintile (RDT+: $64.1 \%$, Micro+: 43.1\%). Malaria was more prevalent among LLIN users (RDT+: 29.5\%, Micro+: 49.1\%) as well as those that used any ever-treated nets (RDT+: 29.5\%, Micro+: $49.0 \%)$. Also, a greater proportion of children whose mothers reported no symptoms of fever in past 2 weeks prior the survey tested positive for malaria parasite on RDT (32.1\%) and microscopy (55.1\%). The most prevalent species of malaria parasite identified from blood film microscopy among U5 children was P. falciparum (93.6\%). Other isolated species include Plasmodium ovale $(5.1 \%)$ and Plasmodium malariae (1.3\%).

Table 2 shows the diagnostic performance of an RDT compared with the microscopy test for malaria diagnosis. Using the microscopy test as a gold standard, RDT was more sensitive than being specific ( $87.6 \%$ vs $75.8 \%)$.

Anaemia was significantly associated with the presence of malaria parasite. Children who were malaria positive showed a higher prevalence of severe anaemia on RDT $+(87.6 \%)$ and Micro+ $(67.4 \%)$ than those who were not anaemic $(\mathrm{RDT}+=31.6 \%$, Micro $+=12.9 \%)$ (Table 3).

The risk of malaria positive RDT and microscopy was significantly lower for children living in houses built with improved floor materials (RDT 35.3\% vs Micro 19.2\%, $\mathrm{p}<0.001)$ compared to those living in houses built with unimproved floor materials (RDT $56.4 \%$ vs Micro $36.9 \%$, $\mathrm{p}<0.001$ ) (Table 4).

This similar pattern was observed for children living in houses built with an improved roof and wall materials. The results further show that children who lived in totally improved houses (RDT $32.4 \%$ vs Micro $17.0 \%$, $\mathrm{p}<0.001$ ) experienced lesser incidence of malaria infection compared to those who lived in houses built with non-improved housing materials (RDT 64.2\% vs Micro $47.1 \%, \mathrm{p}<0.001)$.

\section{Bivariate results}

Table 5 showed the unadjusted and adjusted odds ratio for the relationship between malaria infection from microscopy, socio-demographic characteristics, and types of housing materials. At the unadjusted bivariate level of analysis, the odds of malaria infection were higher among children age $24-59$ months $(\mathrm{OR}=4.49, \mathrm{CI}$ 2.06-9.79), the North West region of Nigeria $(\mathrm{OR}=3.46$, CI 2.78-4.32), in rural areas $(\mathrm{OR}=3.98$, CI 3.42-4.63), in households with the poorest wealth quintile $(\mathrm{OR}=15.61$, CI 11.57-21.06), slept under ever-treated net $(\mathrm{OR}=1.31$, 
Table 1 Distribution of U5 children tested for malaria parasite using RDT or Microscopy and association between test outcomes and selected characteristics

\begin{tabular}{|c|c|c|c|c|c|c|}
\hline \multirow[t]{2}{*}{ Variables } & \multirow[t]{2}{*}{ Number of children } & \multirow[t]{2}{*}{$\%$} & \multicolumn{4}{|c|}{ Malaria test } \\
\hline & & & $\overline{\mathrm{RDT}+}$ & $x^{2} \mathrm{p}$-value & Micro+ & $x^{2} \mathrm{p}$-value \\
\hline \multicolumn{7}{|c|}{ Child's age (months) } \\
\hline $0-6$ & 755 & 10.8 & 21.6 & \multirow[t]{3}{*}{$<0.001^{*}$} & 10.0 & \multirow[t]{3}{*}{$<0.001^{*}$} \\
\hline $7-23$ & 1914 & 27.3 & 36.2 & & 20.3 & \\
\hline $24-59$ & 4342 & 61.9 & 49.5 & & 30.9 & \\
\hline \multicolumn{7}{|l|}{ Sex } \\
\hline Male & 3574 & 51.0 & 46.2 & \multirow[t]{2}{*}{0.063} & 27.8 & \multirow[t]{2}{*}{0.276} \\
\hline Female & 3437 & 49.0 & 44.0 & & 26.9 & \\
\hline \multicolumn{7}{|l|}{ Zone } \\
\hline North Central & 1309 & 18.7 & 50.7 & \multirow[t]{6}{*}{$<0.001^{*}$} & 32.1 & \multirow[t]{6}{*}{$<0.001^{*}$} \\
\hline North East & 983 & 14.0 & 42.9 & & 26.5 & \\
\hline North West & 2286 & 32.6 & 58.2 & & 37.1 & \\
\hline South East & 601 & 8.6 & 31.7 & & 13.9 & \\
\hline South South & 780 & 11.1 & 28.9 & & 19.4 & \\
\hline South West & 1053 & 15.0 & 32.1 & & 15.3 & \\
\hline \multicolumn{7}{|l|}{ Location } \\
\hline Urban & 2350 & 33.5 & 24.1 & \multirow[t]{2}{*}{$<0.001^{*}$} & 11.4 & \multirow[t]{2}{*}{$<0.001^{*}$} \\
\hline Rural & 4661 & 66.5 & 55.7 & & 35.6 & \\
\hline \multicolumn{7}{|l|}{ Usual resident } \\
\hline No & 69 & 1.0 & 36.8 & \multirow[t]{2}{*}{0.147} & 25.2 & \multirow[t]{2}{*}{0.598} \\
\hline Yes & 6942 & 99.0 & 45.2 & & 27.4 & \\
\hline \multicolumn{7}{|l|}{ Wealth quintile } \\
\hline Poorest & 1474 & 21.0 & 64.1 & \multirow[t]{5}{*}{$<0.001^{*}$} & 43.1 & \multirow[t]{5}{*}{$<0.001^{*}$} \\
\hline Poorer & 1612 & 23.0 & 62.7 & & 41.0 & \\
\hline Middle & 1333 & 19.0 & 49.2 & & 27.7 & \\
\hline Richer & 1289 & 18.4 & 30.2 & & 16.8 & \\
\hline Richest & 1303 & 18.6 & 12.7 & & 4.3 & \\
\hline \multicolumn{7}{|c|}{ Slept under ever treated net } \\
\hline No & 3963 & 56.5 & 42.1 & \multirow[t]{2}{*}{$<0.001^{*}$} & 25.7 & \multirow[t]{2}{*}{$<0.001^{*}$} \\
\hline Yes & 3048 & 43.5 & 49.0 & & 29.5 & \\
\hline \multicolumn{7}{|c|}{ Slept under LLITNs } \\
\hline No & 3980 & 56.8 & 42.0 & $<0.001^{*}$ & 25.7 & $<0.001^{*}$ \\
\hline Yes & 3031 & 43.2 & 49.1 & & 29.5 & \\
\hline Dwelling spraye & losquito in last 12 mont & & & & & \\
\hline No & 6867 & 98.6 & 43.9 & $0.006^{*}$ & 27.3 & 0.111 \\
\hline Yes & 95 & 1.4 & 29.9 & & 20.0 & \\
\hline Fever in last $2 \mathrm{w}$ & & & & & & \\
\hline No & 4123 & 59.0 & 37.4 & $<0.001^{*}$ & 23.7 & $<0.001^{*}$ \\
\hline Yes & 2868 & 41.0 & 55.1 & & 32.1 & \\
\hline
\end{tabular}

RDT+: positive on rapid diagnostic test, Micro+: positive on microscopy test

* Significant at $5 \% x^{2}$ test

CI 1.18-1.45) and LLIN (OR=1.32, CI 1.19-1.46). Furthermore, the quality of housing materials versus living in houses with unimproved floor materials $(\mathrm{OR}=2.50$, CI 2.22-2.82), unimproved roof $(\mathrm{OR}=2.92$, CI $2.57-$ 3.33) and unimproved wall materials $(\mathrm{OR}=3.05$, CI 2.70-3.44), and all non-improved building materials
(OR $=4.77, \mathrm{CI} 4.06-5.61)$ were significantly associated with higher risks of malaria infection among U5 children. Indoor spraying of the household was protective against malaria infection.

The adjusted odds ratio for socio-demographic characteristics and types of housing materials associated with 
Table 2 Relationship between the results of the RDT and microscopy tests

\begin{tabular}{llllll}
\hline & $\begin{array}{l}\text { Number } \\
\text { tested }\end{array}$ & \multicolumn{2}{l}{ RDT test } & & \multirow{2}{*}{$\boldsymbol{X}^{\mathbf{2}}$ p-value } \\
\cline { 3 - 4 } & & Positive & Negative & Total & \\
\cline { 3 - 5 } $\begin{array}{l}\text { Number } \\
\text { tested }\end{array}$ & 2387 & 3366 & $5753^{* *}$ & \\
$\begin{array}{l}\text { Microscopy test } \\
\text { Positive }\end{array}$ & 1572 & 87.6 & 12.4 & 27.3 & $<0.001$ \\
Negative & 4181 & 24.2 & 75.8 & 72.7 & \\
Total & $5753^{* *}$ & 41.5 & 58.5 & & \\
\hline
\end{tabular}

The HRP-Il that was used for RDT can only detect. P. falciparum. The P. ovale and $P$. malariae which were found on microscopy also account for the difference between the two tests

RDT+: positive on rapid diagnostic test, Micro+: positive on microscopy test

* Significant at $5 \% x^{2}$ test

** Included only the children that have results for both tests

malaria symptoms showed that their pattern of association with childhood malaria infection remained virtually the same as when the factors were unadjusted for.
However, living in the South West was associated with lower odds of malaria infection among U5 children compared with living in the North Central, North East, North West, South East, and South-South regions.

\section{Multivariate results}

The results in Table 6 shows the adjusted odd ratio for the factors associated with the prevalence of malaria infection (determined by microscopy) among U5 children. There is a significantly-reduced likelihood of malaria infection among U5 if living in an improved housing. In the first model, U5 children who lived in houses built with non-improved materials had higher adjusted odds of having malaria infection $(\mathrm{aOR}=4.8$, CI 4.06-5.61, $\mathrm{p}<0.001)$ than those living in houses built with completely improved materials. This significant association seen in model I was also observed in model II ( $\mathrm{aOR}=4.7, \mathrm{CI} 4.01-5.57, \mathrm{p}<0.001)$. Thus, indicating that indoor residual spraying, sleeping under an ever treated net and or an LLIN does not have an impact on the significant relationship between living in houses built

Table 3 Prevalence of anaemia among malaria positive children

\begin{tabular}{|c|c|c|c|c|c|c|}
\hline Anaemia level & Number tested & $\%$ & RDT+ & $p$-value & Micro+ & $x^{2} \mathrm{p}$-value \\
\hline Severe & 224 & 3.7 & 87.6 & $<0.001^{*}$ & 67.4 & $<0.001^{*}$ \\
\hline Moderate & 2376 & 39.4 & 61.9 & & 40.6 & \\
\hline Mild & 1524 & 25.3 & 37.5 & & 20.6 & \\
\hline Not anaemic & 1905 & 31.6 & 25.1 & & 12.9 & \\
\hline
\end{tabular}

RDT+: positive on rapid diagnostic test, Micro+: positive on microscopy test

* Significant at $5 \% x^{2}$ test

Table 4 The relationship between housing characteristics and malaria infection among under-five children in Nigeria

\begin{tabular}{|c|c|c|c|c|c|c|}
\hline \multirow[t]{2}{*}{ Housing characteristics } & \multirow[t]{2}{*}{$\mathbf{N}$} & \multirow[t]{2}{*}{$\%$} & \multicolumn{4}{|c|}{ Malaria test } \\
\hline & & & $\overline{\mathrm{RDT}+}$ & $p$-value & Micro+ & $x^{2} \mathrm{p}$-value \\
\hline \multicolumn{7}{|l|}{ Floor materials } \\
\hline Unimproved & 3283 & 46.8 & 56.4 & $<0.001^{*}$ & 36.9 & $<0.001^{*}$ \\
\hline Improved & 3728 & 53.2 & 35.3 & & 19.2 & \\
\hline \multicolumn{7}{|l|}{ Roof materials } \\
\hline Unimproved & 1889 & 26.9 & 59.7 & $<0.001^{*}$ & 42.8 & $<0.001^{*}$ \\
\hline Improved & 5122 & 73.1 & 39.7 & & 21.7 & \\
\hline \multicolumn{7}{|l|}{ Wall materials } \\
\hline Unimproved & 3034 & 43.3 & 61.4 & $<0.001^{*}$ & 39.9 & $<0.001^{*}$ \\
\hline Improved & 3977 & 56.7 & 32.9 & & 18.2 & \\
\hline \multicolumn{7}{|l|}{ All building materials } \\
\hline Totally improved & 2969 & 42.4 & 32.4 & $<0.001^{*}$ & 17.0 & $<0.001^{*}$ \\
\hline Partially improved & 2630 & 37.5 & 49.4 & & 28.9 & \\
\hline Nothing improved & 1412 & 20.1 & 64.2 & & 47.1 & \\
\hline Total & 7011 & 100.0 & 45.1 & & 27.3 & \\
\hline
\end{tabular}

RDT+: positive on rapid diagnostic test, Micro+: positive on microscopy test

* Significant at $5 \% X^{2}$ test 
Table 5 Unadjusted and adjusted odds ratio of factors influencing malaria infection using microscopy test results

\begin{tabular}{|c|c|c|c|c|c|c|}
\hline \multirow[t]{2}{*}{ Characteristics } & \multicolumn{3}{|c|}{ Unadjusted estimates } & \multicolumn{3}{|c|}{ Adjusted estimates } \\
\hline & OR & $95 \% \mathrm{Cl}$ & p-value & $\mathrm{aOR}$ & $95 \% \mathrm{Cl}$ & $p$-value \\
\hline \multicolumn{7}{|l|}{ Child age (months) } \\
\hline $0-6$ & 1 & - & & 1 & - & \\
\hline $7-23$ & 2.58 & $1.18-5.67^{*}$ & 0.02 & 2.29 & $1.21-4.34^{*}$ & $<0.01$ \\
\hline $24-59$ & 4.49 & $2.06-9.79^{*}$ & $<0.01$ & 5.67 & $3.01-10.70^{*}$ & $<0.01$ \\
\hline \multicolumn{7}{|l|}{ Zone } \\
\hline South West & 1 & - & & 1 & - & \\
\hline North Central & 2.02 & $1.60-2.55^{*}$ & $<0.01$ & 0.61 & $0.47-0.79^{*}$ & $<0.01$ \\
\hline North East & 1.79 & $1.41-2.27^{*}$ & $<0.01$ & 0.35 & $0.27-0.46^{*}$ & $<0.01$ \\
\hline North West & 3.46 & $2.78-4.32^{*}$ & $<0.01$ & 0.49 & $0.37-0.64^{*}$ & $<0.01$ \\
\hline South East & 0.86 & $0.63-1.16^{*}$ & 0.33 & 0.59 & $0.44-0.79^{*}$ & $<0.01$ \\
\hline South South & 1.28 & $0.99-1.67^{*}$ & 0.06 & 0.42 & $0.31-0.55^{*}$ & $<0.01$ \\
\hline \multicolumn{7}{|l|}{ Location } \\
\hline Urban & 1 & - & & 1 & - & \\
\hline Rural & 3.98 & $3.42-4.63^{*}$ & $<0.01$ & 1.59 & $1.33-1.89^{*}$ & $<0.01$ \\
\hline \multicolumn{7}{|l|}{ Wealth quintile } \\
\hline Richest & 1 & - & & 1 & - & \\
\hline Poorest & 15.61 & $11.57-21.06^{*}$ & $<0.01$ & 5.51 & $3.83-7.93^{*}$ & $<0.01$ \\
\hline Poorer & 13.51 & $10.05-18.16^{*}$ & $<0.01$ & 5.15 & $3.72-7.13^{*}$ & $<0.01$ \\
\hline Middle & 7.06 & $5.22-9.55^{*}$ & $<0.01$ & 3.51 & $2.64-4.65^{*}$ & $<0.01$ \\
\hline Richer & 3.78 & $2.77-5.1 * 8$ & $<0.01$ & 1.89 & $1.46-2.45^{*}$ & $<0.01$ \\
\hline \multicolumn{7}{|c|}{ Slept under ever treated net } \\
\hline No & 1 & - & & 1 & - & \\
\hline Yes & 1.31 & $1.18-1.45^{*}$ & $<0.01$ & 1.21 & $1.08-1.36^{*}$ & $<0.01$ \\
\hline \multicolumn{7}{|l|}{ Slept under LLIN } \\
\hline No & 1 & - & & 1 & - & \\
\hline Yes & 1.32 & $1.19-1.46^{*}$ & $<0.01$ & 1.21 & $1.08-1.36^{*}$ & $<0.01$ \\
\hline \multicolumn{7}{|c|}{ Dwelling sprayed against mosquito in last 12 months } \\
\hline Yes & 1 & - & & 1 & - & \\
\hline No & 1.83 & $1.19-2.85^{*}$ & $<0.01$ & 0.37 & $0.10-1.38$ & 0.14 \\
\hline \multicolumn{7}{|l|}{ Floor materials } \\
\hline Improved & 1 & - & & $1^{* *}$ & - & \\
\hline Unimproved & 2.50 & $2.22-2.82^{*}$ & $<0.01$ & & & \\
\hline \multicolumn{7}{|l|}{ Roof materials } \\
\hline Improved & 1 & - & & $1^{* *}$ & - & \\
\hline Unimproved & 2.92 & $2.57-3.33^{*}$ & $<0.01$ & & & \\
\hline \multicolumn{7}{|l|}{ Wall materials } \\
\hline Improved & 1 & - & & $1^{* *}$ & - & \\
\hline Unimproved & 3.05 & $2.70-3.44^{*}$ & $<0.01$ & & & \\
\hline \multicolumn{7}{|l|}{ All building material } \\
\hline Totally improved & 1 & - & & 1 & - & \\
\hline Partially improved & 2.21 & $1.93-2.54^{*}$ & $<0.01$ & 1.02 & $0.86-1.21$ & 0.82 \\
\hline Nothing improved & 4.77 & $4.06-5.61^{*}$ & $<0.01$ & 1.05 & $1.02-1.12^{*}$ & 0.04 \\
\hline
\end{tabular}

* Significant at $5 \%$ test of logistic regression; ${ }^{* *}$ dropped due to multicollinearity: $O R$ odds ratio, $a O R$ adjusted odds ratio

with completely unimproved materials and contracting malaria. Moreover, controlling for other independent variables greatly reduced the odds of malaria infection when living in a "Nothing improved" housing $(\mathrm{aOR}=1.4$, CI 1.08-1.80, $\mathrm{p}=0.01$ ) observed in model III though the odds ratio was still greater than 1.00 . 
Table 6 Adjusted risk factors for malaria among U5 children based on the microscopic test

\begin{tabular}{|c|c|c|c|c|c|c|}
\hline \multirow[t]{2}{*}{ Characteristics } & \multicolumn{2}{|l|}{ Model I } & \multicolumn{2}{|l|}{ Model II } & \multicolumn{2}{|l|}{ Model III } \\
\hline & OR $(95 \% \mathrm{Cl})$ & p-value & aOR $(95 \% \mathrm{Cl})$ & $p$-value & aOR $(95 \% \mathrm{Cl})$ & p-value \\
\hline \multicolumn{7}{|l|}{ All building materials } \\
\hline Totally improved & 1 & - & & & & \\
\hline Partially improved & $2.21(1.93-2.54)$ & $0.00^{*}$ & $2.21(1.92-2.54)$ & $0.00^{*}$ & $1.03(0.85-1.25)$ & 0.75 \\
\hline Nothing improved & $4.77(4.06-5.61)$ & $0.00^{*}$ & $4.73(4.01-5.57)$ & $0.00^{*}$ & $1.39(1.08-1.80)$ & $0.01^{*}$ \\
\hline \multicolumn{7}{|c|}{ Slept under an ever treated net } \\
\hline No & & & 1 & - & 1 & - \\
\hline Yes & & & $1.16(0.43-3.15)$ & 0.77 & $0.74(0.17-3.18)$ & 0.69 \\
\hline \multicolumn{7}{|l|}{ Slept under LLIN } \\
\hline No & & & 1 & - & 1 & - \\
\hline Yes & & & $0.90(0.33-2.45)$ & 0.84 & $1.11(0.26-4.79)$ & 0.89 \\
\hline \multicolumn{7}{|l|}{ Indoor residual spray } \\
\hline Yes & & & 1 & - & 1 & - \\
\hline No & & & $1.24(0.74-2.08)$ & 0.42 & $1.21(0.64-2.31)$ & 0.56 \\
\hline \multicolumn{7}{|l|}{ Child age (months) } \\
\hline $0-6$ & & & & & 1 & - \\
\hline $7-23$ & & & & & $2.17(0.95-4.97)$ & $0.07^{*}$ \\
\hline $24-59$ & & & & & $4.84(2.13-10.99)$ & $0.00^{*}$ \\
\hline \multicolumn{7}{|l|}{ Zone } \\
\hline South West & & & & & 1 & - \\
\hline North Central & & & & & $0.65(0.47-0.89)$ & $0.01^{*}$ \\
\hline North East & & & & & $0.48(0.35-0.67)$ & $0.00^{*}$ \\
\hline North West & & & & & $0.69(0.50-0.96)$ & $0.03^{*}$ \\
\hline South East & & & & & $0.51(0.35-0.75)$ & $0.00^{*}$ \\
\hline South-South & & & & & $0.70(0.50-0.98)$ & $0.04^{*}$ \\
\hline \multicolumn{7}{|l|}{ Location } \\
\hline Urban & & & & & 1 & - \\
\hline Rural & & & & & $1.54(1.25-1.91)$ & $0.00^{*}$ \\
\hline
\end{tabular}

$O R$ odds ratio $a O R$ adjusted odds ratio

* Significant at $5 \%$ test of logistic regression coefficients significance

Other identified predictors of malaria infection include child's age (24-59 months) and the location of residence. The adjusted odds of malaria infection was about 5 times more likely in older children age 24-59 months $(\mathrm{aOR}=4.8$, CI 2.13-10.99, $\mathrm{p}<0.001)$, and about two times $(\mathrm{aOR}=1.5$, CI 1.25-1.91, $\mathrm{p}<0.001)$ higher in rural areas. However, the likelihood of malaria infection was $0.48(\mathrm{CI}=0.35-0.67, \mathrm{p}<0.001)$ lower in the North East than the South West regions.

\section{Discussion}

Considering the contribution of malaria to under-five morbidities and mortalities in Nigeria, this study is important as it assessed how housing types were related to malaria infection among U5s in Nigeria. This gives an insight into how housing type can contribute to efforts at controlling malaria among U5 children in Nigeria.
Overall, children living in partially improved and nonimproved housing consistently were more likely to have malaria infection compared with those living in improved housing. This likelihood persisted even after adjustment for sleeping under LLINs and indoor spraying which are among the common activities that Nigerians employ in the control of malaria. An earlier study from Uganda did not consider these other control strategies for malaria in their analysis [32]. Our findings gave credence to the idea that better protection from malaria can be achieved by building houses with modern materials in addition to the use of ITN and indoor spraying. Combination of these strategies can create better means of preventing malaria with exponential effect among U5 children in Nigeria and this can improve the overall infant and U5 morbidity and mortality in the country. 
However, following further adjustment for age, region, location, mothers' education and wealth quintile, only non-improved housing still predicted malaria infection among U5. This shows the strong relationship between non-improved housing and malaria infection among U5 and thus makes a strong case for the need to enforce improved housing as a means of controlling malaria among U5 in Nigeria. By tapping into the economic and cultural transition that is ongoing in Africa now, it will be an excellent opportunity to use this new means of malaria prevention to augment existing strategies and improve malaria control among U5 s [24].

The tendency of the older children to have malaria infection compared with the younger ones is likely to be as a result of the maternal antibodies to malaria which was transferred during pregnancy. These antibodies are mainly immunoglobulin $\mathrm{G}$ whose half-life is 6 months [33]. Since the active transfer of the antibody occurs all through pregnancy, the nadir occurs at 6 months of life which explains the reason why the first malaria in children is usually around 6 months of age [34]. The other likely reason for the differential malaria infection rate is the preference of the anopheline mosquitos to bite older children and adults and not infants [35]. The younger infants are also more likely to be breastfeeding and may have the protection of lactoferrin and secretory IgA which have been shown to inhibit malaria parasite growth in vitro [36]. Another reason may also be that the older children will be able to crawl or walk around with less dependence on their mothers, and so, will likely benefit less from the malaria protective behaviours of their mothers. The mothers are more likely to cover their babies' skin with clothing and also wade off or kill the mosquitoes with bare hands. These protective activities will be less available for older children who are no longer so dependent on their mothers. The male children had more malaria infection compared to the females, although the difference was not significant. This may be as a result of the adventurous nature of the males who are more likely to stay more outdoors and as a result, have more mosquito bites.

Anaemia was significantly associated with the presence of malaria parasite which was a consistent finding with earlier studies [37, 38]. Anaemia has been shown to impair growth and cognitive functions among school children $[39,40]$, and in extreme cases, it can result in complicated malaria and death [39]. It is frightening that these children were at home with no form of treatment given to these complications of malaria. The possibility of dying from this complication is high among U5s [39] and this is likely an unnoticed group of children who can potentially contribute to U5 mortality in Nigeria. Public enlightenment targeted at parent could address this and also training of patent medicine sellers from whom many parents seek malaria treatment for their wards.

The inverse relationship between U5 malaria infection and wealth quintile is not surprising as people with higher wealth quintile were more likely to be able to afford improved houses and more likely to be educated and have better access to knowledge about steps to prevent malaria infection $[21,41]$. They were also more likely to be able to afford ITN and be able to use them correctly as well as be able to afford insecticides used for indoor spraying. In addition, people in the higher wealth quintile are more likely to be found in urban areas.

The rural dwellers, on the other hand, were more likely to have factors that promote malaria transmission generally aside from non-improved housing, like bushes and inappropriate waste disposal (which present excellent breeding spaces for mosquitos), reduced access to ITN, indoor sprays and lack of knowledge of steps to prevent malaria infection. Persons living in urban environment have greater likelihood of having improved houses, higher socioeconomic status and limited number of breeding sites [42] and thus, lower likelihood of malaria infection. However, urban malaria continues to be a concern globally since it accounts for $6-28 \%$ of the projected annual malaria incidence [43].

Children resident in South west Nigeria were more likely to have malaria infection than children from the other parts. Different factors have been described to influence the prevalence, distribution, and transmission of malaria vectors as it relates to recent changes in climatic and environmental factors [44].

In this study, children who ever used ITN or were current users of ITN were more likely to have a malaria infection. This finding is of serious concerns because it contravenes the expectation that the use of ITN will protect them from malaria. This is probably due to the fact that children were only put to net-use after they might have been exposed to malaria or possibly because of living in malaria-prone areas. Other possible reasons why malaria is more prevalent among ITN users are diminishing bioefficacy of the nets, lowered susceptibility of the mosquitoes to pyrethroid insecticides, wrong use of the ITNs, use of ITNs with holes, and the habit of sleeping on the couch in the living room before sleeping under a treated net [45]. This calls for a holistic approach to malaria prevention like indoor residual spraying, living in an improved housing and maintaining a clean environment.

Some limitations were identified in this study. It was not clear if the children with features of severe malaria were already on antimalarial drugs when they were seen so we were not sure the parents identified these complications and sought for help before the study identified 
them. The differences in the specificity and sensitivity of the diagnostic methods (RDT and microscopy) and how sampling strategy was conducted which may be biased to certain people in the population are worthy of mention.

\section{Conclusion}

Housing type is an essential risk factor for malaria occurrence among U5 children in Nigeria. Non-improved housing predicted malaria infection among U5 in this study. Also, older children, those living in rural areas and children from the poorest households were most affected. Improved housing is a promising means to support a more integrated and sustainable approach to malaria prevention, and ending the incidence of malaria as stipulated in the Nigeria national malaria policy and target 3.3 of Goal 3 of the sustainable development goals. Education of the Nigerian people on the malaria protection role of modern housing and empowerment to encourage the adoption of modern house design in addition to other malaria preventive strategies can help to augment the current malaria control measures among U5 children.

\begin{abstract}
Abbreviations
U5: under-five; RDT: rapid diagnostic test; OR: odds ratio; Cl: confidence interval; NDHS: Nigeria Demographic and Health Surveys; EAs: enumeration areas; LLINs: long-lasting insecticide-treated nets; IRS: indoor residual spraying; ACT: artemisinin-based combination therapy; IPTp: intermittent preventive therapy for pregnant women; RBM: Roll Back Malaria; AIM: Action and Investment to Defeat Malaria; FCT: Federal Capital Territory; NMIS: Nigeria Malaria Indicator Survey; NMEP: National Malaria Elimination Programme; NPC: National Population Commission; NBS: National Bureau of Statistics; LGAs: Local Government Areas; Micro+: positive on microscopy; ITN: insecticide-treated net.
\end{abstract}

\section{Authors' contributions}

$\mathrm{OMM}, \mathrm{FMB}$ and AFF conceived the study, developed the research questions, and wrote the method section. AFF analysed the data, wrote the methods and results while $\mathrm{OMM}$ and FMB wrote the introduction and discussion sections respectively. All authors read and approved the final manuscript.

\begin{abstract}
Author details
${ }^{1}$ Department of Environmental Health Sciences, Faculty of Public Health, College of Medicine, University of Ibadan, Ibadan, Nigeria. ${ }^{2}$ Institute of Child Health, College of Medicine, University of Ibadan, Ibadan, Nigeria. ${ }^{3}$ Department of Epidemiology and Medical Statistics, Faculty of Public Health, College of Medicine, University of Ibadan, Ibadan, Nigeria.
\end{abstract}

\section{Acknowledgements}

We are grateful to the National Malaria Elimination Programme, the National Population Commission and the National Bureau of Statistics, Abuja, Nigeria. The authors thank the National Population Commission and ICF Macro Calverton, Maryland, USA for releasing the data for this study. We also acknowledge the technical support received from the Consortium for Advanced Research Training in Africa (CARTA). The authors are CARTA fellows and they received training in research conception and manuscript writing.

\section{Competing interests}

The authors declare that they have no competing interests.

\section{Availability of data and materials}

The data that support the findings of this study are available from MEASURE DHS but restrictions apply to the availability of these data, which were used under license for the current study, and so are not publicly available. Data are however available from MEASURE DHS upon reasonable request and with permission from http://www.dhsprogram.com.

\section{Consent for publication}

Not applicable.

\section{Ethics approval and consent to participate}

The ethical approval for the study protocol was obtained from the ICF International's Institutional Review Board and the Nigerian National Health Research Ethics Committee (NHREC), number NHREC/01/01/2007-11/05/2015. Moreover, informed consent was obtained from study participants prior data collection. The details of ethical approval and guidelines for the conduct of the research had been reported in an earlier report [28].

\section{Funding}

No funding was available for this study.

\section{Publisher's Note}

Springer Nature remains neutral with regard to jurisdictional claims in published maps and institutional affiliations.

Received: 1 June 2018 Accepted: 23 August 2018

Published online: 28 August 2018

\section{References}

1. Wassmer CS, Grau GER. Severe malaria: what's new on the pathogenesis front? Int Parasitol. 2017;47:145-52.

2. WHO. World malaria report 2015. Geneva: World Health Organization; 2015.

3. WHO. World malaria report 2016. Geneva: World Health Organization; 2016.

4. Dawaki S, Al Mekhlafi HM, Ithoi I, Ibrahim J, Atroosh WM, Abdulsalam AM, et al. Is Nigeria winning the battle against malaria? Prevalence, risk factors and KAP assessment among Hausa communities in Kano State. Malar J. 2016;15:351.

5. National Population Commission (Nigeria). National Malaria Control Programme, ICF International. Nigeria Malaria Indicator Survey 2010. Nigeria; 2012. Available from: http://dhsprogram.com/publications/publicatio n-MIS8-MIS-Final-Reports.Cfm. Accessed 11 Aug 2017.

6. Marsh K, Forster D, Waruiru C, Mwangi I, Winstanley M, Marsh V, et al. Indicators of life-threatening malaria in African Children. N Engl J Med. 1995:332:1399-404.

7. Mishra SK, Newton CR. Diagnosis and management of the neurological complications of falciparum malaria. Nat Rev Neurol. 2009;5:189-98.

8. Holding PA, Kitsao-Wekulo PK. Describing the burden of malaria on child development: what should we be measuring and how should we be measuring it? Am J Trop Med Hyg. 2004;71:71-9.

9. White NJ. Review series Antimalarial drug resistance. J Clin Invest. 2004;113:1084-92.

10. Nkumama IN, O'Meara WP, Osier FHA. Changes in malaria epidemiology in Africa and new challenges for elimination. Trends Parasitol. 2017:33:128-40.

11. Pinder M, Conteh L, Jeffries D, Jones C, Knudsen J, Kandeh B, et al. The RooPfs study to assess whether improved housing provides additional protection against clinical malaria over current best practice in The Gambia: study protocol for a randomized controlled study and ancillary studies. Trials. 2016;17:275.

12. Ranson H, N'Guessan R, Lines J, Moiroux N, Nkuni Z, Corbel V. Pyrethroid resistance in African anopheline mosquitoes: what are the implications for malaria control? Trends Parasitol. 2011;27:91-8.

13. WHO. Atlas of insecticide resistance in malaria vectors of the WHO African region. Harare: World Health Organization; 2005.

14. Edi CVA, Koudou BG, Jones CM, Weetman D, Ranson H. Multiple-insecticide resistance in Anopheles gambiae mosquitoes, southern Cote d'Ivoire. Emerg Infect Dis. 2012;18:1508-11.

15. Ochomo EO, Bayoh NM, Walker ED, Abongo BO, Ombok MO, Ouma C, et al. The efficacy of long-lasting nets with declining physical integrity 
may be compromised in areas with high levels of pyrethroid resistance. Malar J. 2013;12:368.

16. Toé $\mathrm{KH}$, Jones $\mathrm{CM}$, N'Fale S, Ismail HM, Dabiré RK, Ranson H. Increased pyrethroid resistance in malaria vectors and decreased bed net effectiveness, Burkina Faso. Emerg Infect Dis. 2014;20:1691-6.

17. Busvine JR. Current problems in the control of mosquitoes. Nature. 1978;273:604-7.

18. Busvine JR, Pal R. The impact of insecticide-resistance on control of vectors and vector-borne diseases. Bull World Health Organ. 1969;40:731-44.

19. Kelly-hope L, Ranson H, Hemingway J. Lessons from the past: managing insecticide resistance in malaria control and eradication programmes. Lancet Infect Dis. 2008;8:387-9.

20. RBM. Housing and Malaria. 2015

21. RBM, UNDP. Multisectoral action framework for malaria. New York: UNDP; 2013

22. Braubach $M$, Fairburn J. Social inequities in environmental risks associated with housing and residential location - a review of evidence. Eur J Public Health. 2010;20:36-42.

23. Konradsen F, Amerasinghe P, van der Hoek W, Amerasinghe F, Perera D, Piyaratne M. Strong association between house characteristics and malaria vectors in Sri Lanka. Am J Trop Med Hyg. 2003;68:177-81.

24. Lindsay SW, Jawara M, Paine K, Pinder M, Walraven GEL, Emerson PM. Changes in house design reduce exposure to malaria mosquitoes. Trop Med Int Health. 2003;8:512-7.

25. Byrd I. Mosquitoes: role of certain species in prevalence of malaria. New Orleans Med Surg J. 1914;67:1417.

26. Boyd MF. The influence of obstacles unconsciously erected against anophelines (housing and screening) upon the incidence of malaria. Am J Trop Med Hyg. 1926;6:157-60.

27. Reiter $P$, Lathrop $S$, Bunning $M$, Biggerstaff $B$, Singer $D$, Tiwari T, et al. Texas lifestyle limits transmission of dengue virus. Emerg Infect Dis. 2003;9:86-9.

28. NMEP NMEP, NPopC NPC, NBS N of B, Statistics, ICF International. Nigeria Malaria Indicator Survey 2015. Abuja, Nigeria; 2016.

29. Adebowale SA, Morakinyo OM, Ana GR. Housing materials as predictors of under-five mortality in Nigeria: evidence from 2013 demographic and health survey. BMC Pediatr. 2017;17:30.

30. National Population Commission (Nigeria), ICF International. Nigeria Demographic and Health Survey 2013. Abuja: National Population Commission (Nigeria) and ICF International; 2014.

31. Carvajal-Vélez L, Amouzou A, Perin J, Maïga A, Tarekegn H, Akinyemi A, et al. Diarrhea management in children under five in sub-Saharan Africa: does the source of care matter? A Countdown analysis. BMC Public Health. BMC Public Health. 2016:16:830.
32. Wanzirah H, Tusting LS, Arinaitwe E, Katureebe A, Maxwell K, Rek J, et al. Mind the gap: house structure and the risk of malaria in Uganda. PLoS ONE. 2015:10:e0117396.

33. Charnaud SC, Mcgready R, Herten-crabb A, Powell R, Guy A, Langer C, et al. Maternal-foetal transfer of Plasmodium falciparum and Plasmodium vivax antibodies in a low transmission setting. Sci Rep. 2016;6:20859.

34. Snow R, Nahlen B, Palmer A, Donnelly C, Gupta S, Marsh K. Risk of severe malaria among African infants: direct evidence of clinical protection during early infancy. J Infect Dis. 1998;177:819-22.

35. Dobbs KR, Dent AE. Plasmodium malaria and antimalarial antibodies in the first year of life. Parasitology. 2016;143:129-38.

36. Kassim O, Ako-Anai K, Torimiro S, Hollowell G, Okoye V, Martin S. Inhibitory factors in breastmilk, maternal and infant sera against in vitro growth of Plasmodium falciparum malaria parasite. J Trop Pediatr. 2000;46:92-6.

37. Kimbi HK, Sumbele IUN, Nweboh M, Anchang-Kimbi JK, Lum E, Nana Y, et al. Malaria and haematologic parameters of pupils at different altitudes along the slope of Mount Cameroon: a cross-sectional study. Malar J. 2013;12:193.

38. Das BS, Thurnham DI, Das DB. Influence of malaria on markers of iron status in children: implications for interpreting iron status in malariaendemic communities. Br J Nutr. 1997;78:751-60.

39. Orimadegun A, Fawole O, Okereke J, Akinbami F, Sodeinde O. Increasing burden of childhood severe malaria in a Nigerian tertiary hospital: implication for control. J Trop Pediatr. 2007;53:185-9.

40. Fernando $D$, de Silva $D$, Wickremasinghe R. Short-term impact of an acute attack of malaria on the cognitive performance of schoolchildren living in a malaria-endemic area of Sri Lanka. Trans R Soc Trop Med Hyg. 2003;97:161-5.

41. Ye Y, Hoshen MB, Louis VR, Seraphin S, Traore I, Sauerborn R. Housing conditions and Plasmodium falciparum infection: protective effect of ironsheet roofed houses. Malar J. 2006:5:8.

42. Hay S, Guerra C, Tatem A, Atkinson P, Snow R. Opinion - tropical infectious diseases: urbanization, malaria transmission and disease burden in Africa. Nat Rev Microbiol. 2005;3:81-90.

43. Keiser J, Utzinger J, Caldas de Castro M, Smith T, Tanner M, Singer B. Urbanization in sub-saharan Africa and implication for malaria control. Am J Trop Med Hyg. 2004;71:118-27.

44. Odongo-Aginya E, Ssegwanyi G, Kategere P, Vuzi PC. Relationship between malaria infection intensity and rainfall pattern in Entebbe peninsula, Uganda. Afr Health Sci. 2005:5:238-45.

45. Atieli HE, Zhou G, Afrane Y, Lee M, Mwanzo I, Githeko AK, et al. Insecticide-treated net (ITN) ownership, usage, and malaria transmission in the highlands of western Kenya. Parasit Vectors. 2011;4:113.
Ready to submit your research? Choose BMC and benefit from:

- fast, convenient online submission

- thorough peer review by experienced researchers in your field

- rapid publication on acceptance

- support for research data, including large and complex data types

- gold Open Access which fosters wider collaboration and increased citations

- maximum visibility for your research: over $100 \mathrm{M}$ website views per year

At BMC, research is always in progress.

Learn more biomedcentral.com/submissions 